\title{
A Role for Electrotonic Coupling in the Striatum in the Expression of Dopamine Receptor-mediated Stereotypies
}

Holly Moore, Ph.D., and Anthony A. Grace, Ph.D.

Stimulation of dopamine $(D A)$ receptors in the striatum evokes a number of alterations in motor behavior in rats, as well as causing several alterations in cellular physiology, including changes in membrane potential, cell excitability, afferent drive, and electrotonic coupling. One cellular property that is potently modulated by DA stimulation is electrotonic coupling, a process shown to subserve motor pattern generation. To examine whether electrotonic coupling plays a role in mediating a specific set of DA receptor-mediated motor behaviors, we tested the effects of two inhibitors of gap junction conductance, carbenoxolone $(C A R B)$ and anandamide (AEA), on apomorphine (APO)induced motor responses. We then used intra-striatal infusions of CARB to determine the role of electrotonic coupling specifically in the ventral striatum in the expression of APO-induced behaviors. APO (2.5-3.0 mg/ $\mathrm{kg}$, i.p.) significantly increased motor activity (a composite score) and the frequencies of oral and sniffing stereotypies. $A P O$ also disrupted grooming initiation and completion. APO-induced oral stereotypies were selectively blocked by systemic administration of CARB $(7.0,35.0 \mathrm{mg} / \mathrm{kg})$.
Moreover, although CARB alone disrupted the initiation and completion of grooming sequences, it also partially normalized APO-induced disruptions in grooming. AEA $(0.5,1.5 \mathrm{mg} / \mathrm{kg})$ also blocked APO-induced oral stereotypies at the higher dose, but differed from CARB in that it did not restore normal grooming behaviors but, instead, appeared to "release" locomotion. Bilateral infusion of carbenoxolone (50 pmol) into the ventral striatum also blocked the oral stereotypies induced by systemic APO. We conclude from these and previous experiments that gap junctions play an important role in normal motor behavior, and furthermore that disruption of motor behavior in the form of oral and sniffing stereotypies associated with systemic APO administration may be a consequence of this heightened electrotonic coupling in the striatum. These results may be relevant to diseases and pharmacotherapies associated with disruptions of motor and possibly cognitive sequencing. [Neuropsychopharmacology 27:980-992, 2002] (C) 2002 American College of Neuropsychopharmacology. Published by Elsevier Science Inc.
From the Departments of Neuroscience and Psychiatry, University of Pittsburgh, Pittsburgh, PA 15260 USA.

Address correspondence to: Anthony A. Grace, Department of Neuroscience, 458 Crawford Hall, University of Pittsburgh, Pittsburgh, PA 15260. E-mail: Grace@bns.pitt.edu

Current address: Holly Moore, Ph.D. Columbia University, Department of Psychiatry, 1051 Riverside Dr., Mail Box 14, New York, NY 10032. E-mail: hm2035@columbia.edu

Received February 20, 2002; revised May 24, 2002; accepted May 30, 2002.

Online publication: 6/3/02 at www.acnp.org/citations/ Npp060302317.
KEY WORDS: Gap junction; Apomorphine; Carbenoxolone; Anandamide; Motor activity; Grooming; Oral behaviors; Sniffing stereotypy

Adaptive behaviors, both learned and spontaneous, consist of sequences of "micro" movements executed by closely-related muscle groups. There is evidence that the initiation and execution of individual movements, such as oral movements involved in feeding, as well as the linking of these movements into a behavioral sequence, depend upon neuronal networks within the 
striatum (Aldridge and Berridge 1998; Aldridge et al. 1993; Cromwell and Berridge 1996; Matsumoto et al. 1999). Motor initiation and sequencing are also potently modulated by dopamine (DA) transmission in the striatum, as evidenced by the disruptive effects of DA denervation on both initiation and sequencing of movements. Moreover, downregulation or antagonism of DA D1 receptors with genetic, antisense, or pharmacologic techniques can disrupt sequencing per se (i.e. individual behaviors are expressed, but not sequentially (Berridge and Aldridge 2000a,b; Cromwell et al. 1998). Consistent with this, D1 receptor stimulation promotes the completion of complex behavioral sequences such as grooming (Molloy and Waddington 1984a). On the other hand, whereas blockade or genetic inactivation of D2 receptors impairs the initiation of movements (Fowler and Liou 1994; Horikawa et al. 1997; Sibley 1999), stimulation of D2 receptors by non-selective or D2-selective agonists produces repetition of simple behaviors such as licking, gnawing, or sniffing stereotypy (Abrams and Bruno 1992; Beninger et al. 1991; Braun and Chase 1986; Byrnes et al. 1994; Delfs and Kelley 1990). Thus, in the context of behavioral sequencing, the simple 'repetitive' stereotypy (Berridge and Aldridge 2000a) produced by D2 receptor over-stimulation in the striatum (Delfs and Kelley 1990) can be seen as the inability to release one 'simple' behavior in order to allow initiation of the next simple behavior in a normal, adaptive sequence (Pedro et al. 1994; Szechtman et al. 1999).

One means by which neuronal networks may interact within the striatum is via communication among clusters of functionally related striatal neurons. Such a network interaction may be mediated via gap junctions. It is well-established that electrotonic transmission between developing neurons is important in the formation and stabilization of functional networks (Bannerman et al. 2000; Peinado et al. 1993; Roerig and Feller 2000). However, there is also evidence that in the adult brain, electrotonic coupling directly mediates forms of neuronal network activity (Bou-Flores and Berger 2001; Jefferys 1995; Perez Velazquez and Carlen 2000) which, in turn, contribute to rhythmic behavioral patterning (Bou-Flores and Berger 2001; Rothwell 1998). Thus, it is likely that motor patterning may involve activity within neuronal networks coordinated via gap junctions. In the striatum, cells express connexins, the protein building blocks of gap junctions (Belluardo et al. 2000; Bennett et al. 1999). Striatal neurons also exhibit dye coupling, the transfer of dye molecules between neurons through electrotonic junctions (Cepeda et al. 1989). Moreover, like behavioral sequencing, dye coupling between neurons in the striatum is potently modulated by DA receptor activation (Cepeda et al. 1989; Onn and Grace 1994, 1995, 1999). In the present study, it was postulated that electrotonic coupling within the striatum might subserve network processes that, in turn, modu- late behavioral sequencing. Therefore, disruption of gap junctions may ultimately interfere with such behavioral sequencing. We examined whether gap junctions may play a role in behavioral patterns by testing the effects of gap junction inactivators on the motor behavior elicited by the DA agonist apomorphine. Apomorphine administration is known to evoke a broad range of DA-mediated behaviors, including hyperlocomotion, rearing, sniffing, and stereotypy. In addition, we found acute apomorphine administration to lead to a marked increase in both the incidence and extent of dye coupling among neurons in the dorsal striatum (Onn and Grace 1994). The response to apomorphine was examined during administration of the gap junction inactivators carbenoxolone (CARB) and anandamide (AEA) because of their shared effectiveness in blocking gap junction conductance or electrotonic coupling in brain tissue but lack of similarity in their other cellular or behavioral effects. Carbenoxolone is a moderately lipophilic glycyrrhetinic acid derivative that has been shown to act directly on gap junctions in brain and other tissues to reduce conductance by up to $80 \%$, although the exact mechanism underlying this effect remains to be determined (Davidson and Baumgarten 1988; Rozental et al. 2001). It inhibits gastric pepsins (Roberts and Taylor 1980) and has a number of mineralocorticoid actions (Armanini et al. 1982), including inhibition of 11- $\beta$-dehyrogenase and 11-oxoreductase (Stewart et al. 1990). Anandamide, on the other hand, is a highly lipophilic arachidonic acid-derived ethanolamide that has been shown to block gap junction transmission (Boger et al. 1999), more specifically, in striatum (Venance et al. 1995). At doses at or above $10 \mathrm{mg} / \mathrm{kg}$ it acts as an agonist at central cannabinoid CB1 receptors, producing catalepsy and hypothermia (Costa et al. 1999; Crawley et al. 1993; Fride and Mechoulam 1993). It also acts at peripheral CB1 (De Petrocellis et al. 1998) and vanillin receptors (De Petrocellis et al. 2001), actions possibly related to its analgesic effects. Thus, although actions of CARB and AEA have not been fully characterized, there appears to be little overlap in their pharmacological or physiological effects besides gap junction inactivation. Therefore, we used these drugs to determine if a class of dopamine receptormediated behaviors depends on electronic coupling in general and, more specifically, within the striatum.

\section{MATERIALS AND METHODS}

\section{Subjects}

Naïve male Sprague-Dawley rats three to six months of age were double-housed in a 12:12 h light/dark cycle, lights on at 7 A.M., with food and water available ad libitum (Hilltop Laboratories, Scottdale, PA). All animals were tested during the first $4 \mathrm{~h}$ of the dark cycle (between 7 and 11 P.M.). All procedures were conducted 
according to the NIH Guide for the Care and Use of Laboratory Animals and were approved by the University of Pittsburgh Institutional Animal Care and Use Committee.

\section{Drugs}

Carbenoxolone (Sigma, St. Louis, MO) and anandamide (RBI, Natick, MA) were dissolved by adding 10 microliters of $70 \%$ ethanol then bringing the solution to a volume of $1.0 \mathrm{~mL}$ with $0.05 \mathrm{M}$ saline. This mixture was then placed in an ultrasonic bath for 10-15 min until the drug was dissolved or completely suspended. Apomorphine hydrochloride (RBI) was dissolved in distilled water. Systemic injections were given at $1 \mathrm{ml} / \mathrm{kg}$. Controls were injected with the vehicle used for each drug.

\section{Measurement of Motor Activity and Stereotypy}

Rats were tested during the dark cycle in an $461 \times 20 \mathrm{w} \times$ $20 \mathrm{~h}(\mathrm{~cm})$ polycarbonate tub with the floor divided into quadrants. The motor activation scale, adapted from Byrnes et al. (1994), was modified based on the doseand time-dependent effect of apomorphine (APO) on motor activity as determined in pilot experiments and reported by others (Abrams and Bruno 1992; Braun and Chase 1986). The progression of APO-induced motor activity followed the following scale:

0 . inactive

1. intermittent head or forepaw movement; normal exploratory behavior within a quadrant

2. bouts of continuous head (including sniffing) or forepaw movement; locomotion involving one or two quadrants

3. locomotion and sniffing across two 2 or more quadrants

4. continuous locomotion and sniffing

5. continuous sniffing localized to one area of the tub; intermittent oral stereotypy

6. continuous oral stereotypy (licking, mouthing, gnawing)

Simple repetitive stereotypies, including sniffing, licking, mouthing, and gnawing, were also scored individually as not present $(0)$, intermittent $(1$; bouts $<15 \mathrm{~s})$, or constant (2; bouts $>1 \mathrm{~min}$ ). Grooming behaviors, including paw wash, face/head wash, and hindflank wash were each recorded. Grooming sequence initiation and grooming sequence completion were scored post-hoc using criteria based on those of Aldridge and Berridge (Aldridge and Berridge 1998; Berridge and Aldridge 2000a,b). Specifically, a paw wash initiated as the first grooming behavior in a scoring period was considered "grooming sequence initiation" (Phase I). If paw wash was followed by face or head wash (Phases II or III) and flank wash, then the flank wash was scored as "grooming sequence completion" (Phase IV).

\section{Experiment 1: The Effect of Systemic Administration of Gap Junction Inactivators on Apomorphine-induced Stereotypy}

Carbenoxolone and AEA were tested independently. For each gap junction inactivator, rats were divided into five groups. The VEH-VEH group received the vehicle of the gap junction inactivator (VEH1) followed by injection of the vehicle for apomorphine (VEH2). The second group received CARB $(35.0 \mathrm{mg} / \mathrm{kg})$ or AEA $(1.5$ $\mathrm{mg} / \mathrm{kg}$ ) followed by VEH2. The third group received VEH1 followed by APO. The fourth group received a lower dose of CARB $(7.0 \mathrm{mg} / \mathrm{kg})$ or AEA $(0.5 \mathrm{mg} / \mathrm{kg})$ then APO. The fifth group received the higher dose of CARB $(35.0 \mathrm{mg} / \mathrm{kg})$ or AEA $(1.5 \mathrm{mg} / \mathrm{kg})$ prior to receiving APO. APO from different batches appeared to have different efficacies, so the dose was adjusted from $2.5-3.0 \mathrm{mg} / \mathrm{kg}$ to produce equivalent levels of stereotypy among VEH1-APO groups. All drugs were injected intraperitoneally (i.p.). The two injections were spaced by $15 \mathrm{~min}$.

Experiment 2: The Effect of Intra-striatal Infusion of Carbenoxolone on Stereotypy Induced by Systemic Administration of Apomorphine

Guide cannulae (28 gauge., Plastics One) were implanted bilaterally into the central ventral striatum at $0.5-1.0 \mathrm{~mm}$ anterior to Bregma, $1.5-2.5 \mathrm{~mm}$ lateral to the midline and $5 \mathrm{~mm}$ ventral to the skull surface according to the atlas of Paxinos and Watson (1986). Animals were allowed to recover for three days prior to testing. During this time and before surgery they were habituated to the restraint procedure used for intracranial injection. During testing, animals were gently restrained by slipping two forefingers over the snout. Needles (30 gauge) filled with carbenoxolone $(10 \mu \mathrm{M})$ were then inserted into the cannulae. Needles extended $1.0 \mathrm{~mm}$ beyond the tip of the guide cannulae. A volume of 0.5 microliters per side of CARB or VEH1 was infused over $2 \mathrm{~min}$. The needles were then left in place and the inlet tubing was cut close to the inlet of the cannulae. Ten minutes following the intra-striatal infusion, APO $(3.0 \mathrm{mg} / \mathrm{kg})$ was administered systemically (i.p.).

\section{Statistical Analyses}

Effects of each gap junction inactivator on spontaneous (baseline) and APO-induced activity (activity score), ambulation (number of quadrant crossings), and oral and sniffing stereotypies were analyzed independently for each dependent variable by first applying a mixed ANOVA using Drug condition as a factor and Time after APO administration as the repeated measure. In cases in which there was no significant effect of Time or Time $X$ Drug interaction, the dependent variable was averaged 


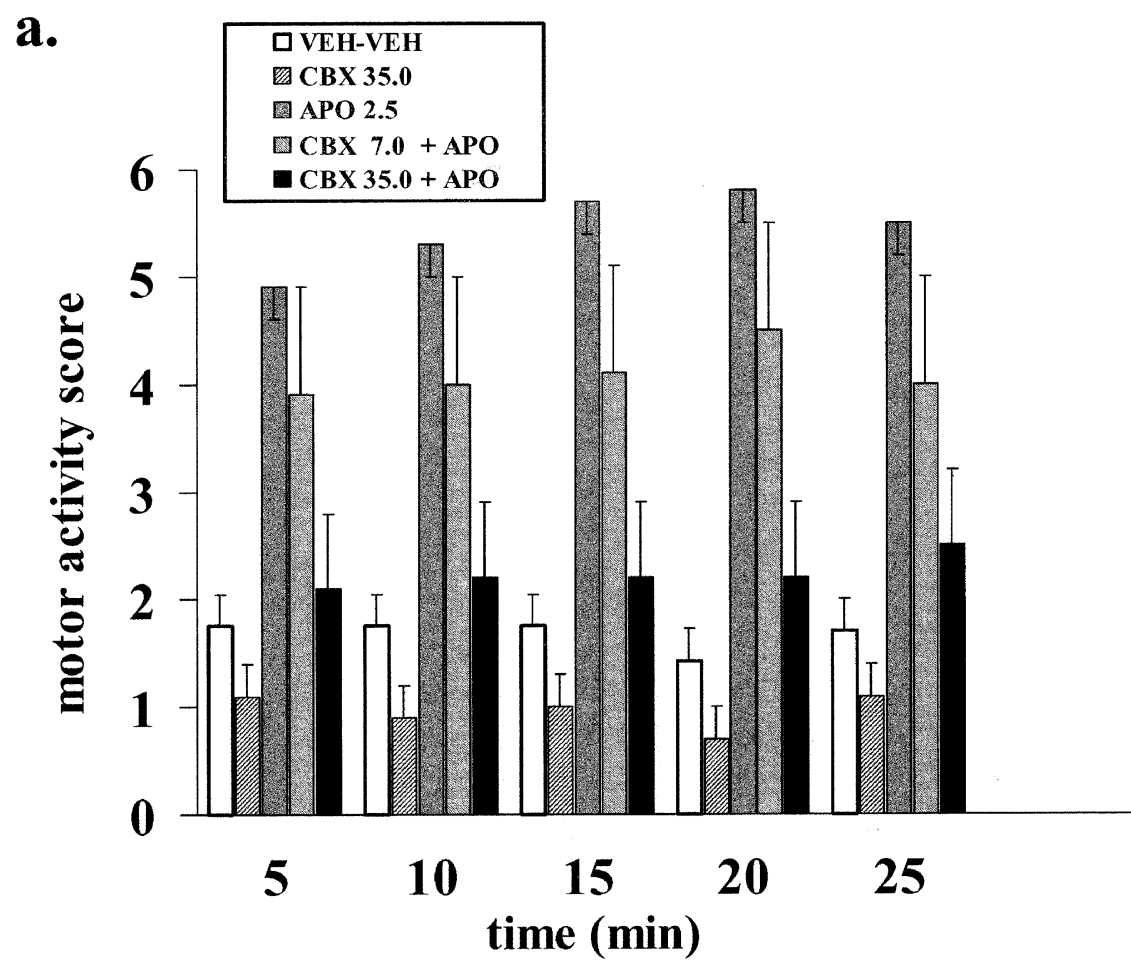

b.

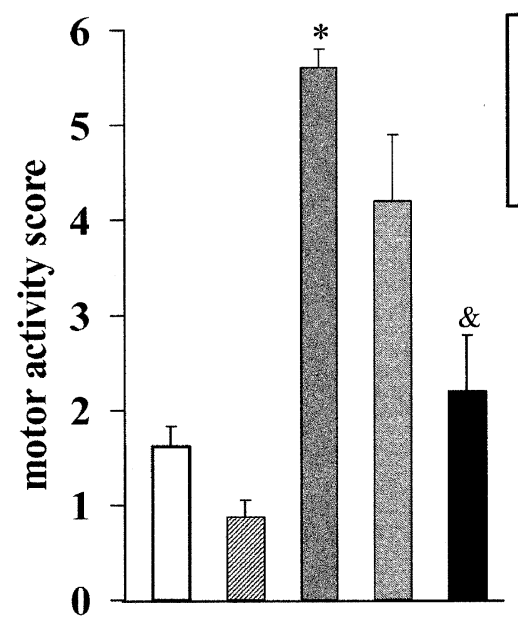

over the period from 10-25 min after APO administration and a 1-way ANOVA with Tukey's post-hoc comparisons was used to test for differences among drug conditions. The proportion (frequency) of animals exhibiting grooming initiation and completion were compared across conditions with the binomial test. All statistical tests were conducted using SPSS software (SPSS, Inc., Chicago, IL).

\section{RESULTS}

\section{Experiment 1a. Effects of Systemic Administration of CARB on the Behavioral Effects of APO}

The following groups were included in the analyses described below: VEH1-VEH2 ( $\mathrm{n}=7)$, CARB $(35.0 \mathrm{mg}$ /
Figure 1. (a) Total motor activity (reflecting both locomotion and stereotypy) following injection (i.p. $1.0 \mathrm{ml} /$ $\mathrm{kg}$ ) of saline (open, $\mathrm{n}=7$ ), carbenoxolone (CARB; $35.0 \mathrm{mg} / \mathrm{kg}$; rightwardhatched, $\mathrm{n}=11)$, apomorphine (APO; $2.5 \mathrm{mg} / \mathrm{kg}$; dark gray, $\mathrm{n}=12$ ), or CARB $7.0 \mathrm{mg} / \mathrm{kg}$ (light gray, $\mathrm{n}=8$ ) or $35 \mathrm{mg} / \mathrm{kg}$ (black, $\mathrm{n}=10$ ) followed 15 min by APO. (b) Motor activity averaged during the period of the peak effect of APO (10-25 min post-APO). APO significantly increased motor activity at all time points; this effect was significantly antagonized by the higher dose of CARB (see text). ${ }^{*} p<.05$ relative to VEH-VEH; \& $p<.05$ relative to $\mathrm{APO}$, and not significantly different from VEH-VEH.
$\mathrm{kg})$-VEH2 ( $\mathrm{n}=11)$, APO-VEH2 $(\mathrm{n}=12)$, CARB (7.0 $\mathrm{mg} / \mathrm{kg})$-APO and CARB $(35.0 \mathrm{mg} / \mathrm{kg})$-APO $(\mathrm{n}=10)$.

Locomotion and Simple Stereotypies. A 2-way ANOVA analyzing the effects of drugs over the period from 5 to 25 min following APO administration revealed neither a main effect of Time nor a Time $X$ Drug interaction (Figure 1, panel a). Therefore, the effects of drug treatment were analyzed with a 1-way ANOVA using the average motor activity score for the period of 10-25 $\mathrm{min}$ following APO administration. This analysis revealed a significant effect of drug treatment $\left(\mathrm{F}_{4,43}=23.4, p<\right.$ .001; Figure 1, panel b). Tukey's post-hoc comparisons revealed that CARB-VEH animals did not significantly differ from controls but APO animals showed a significant increase in motor activity. CARB dose-depen- 
a
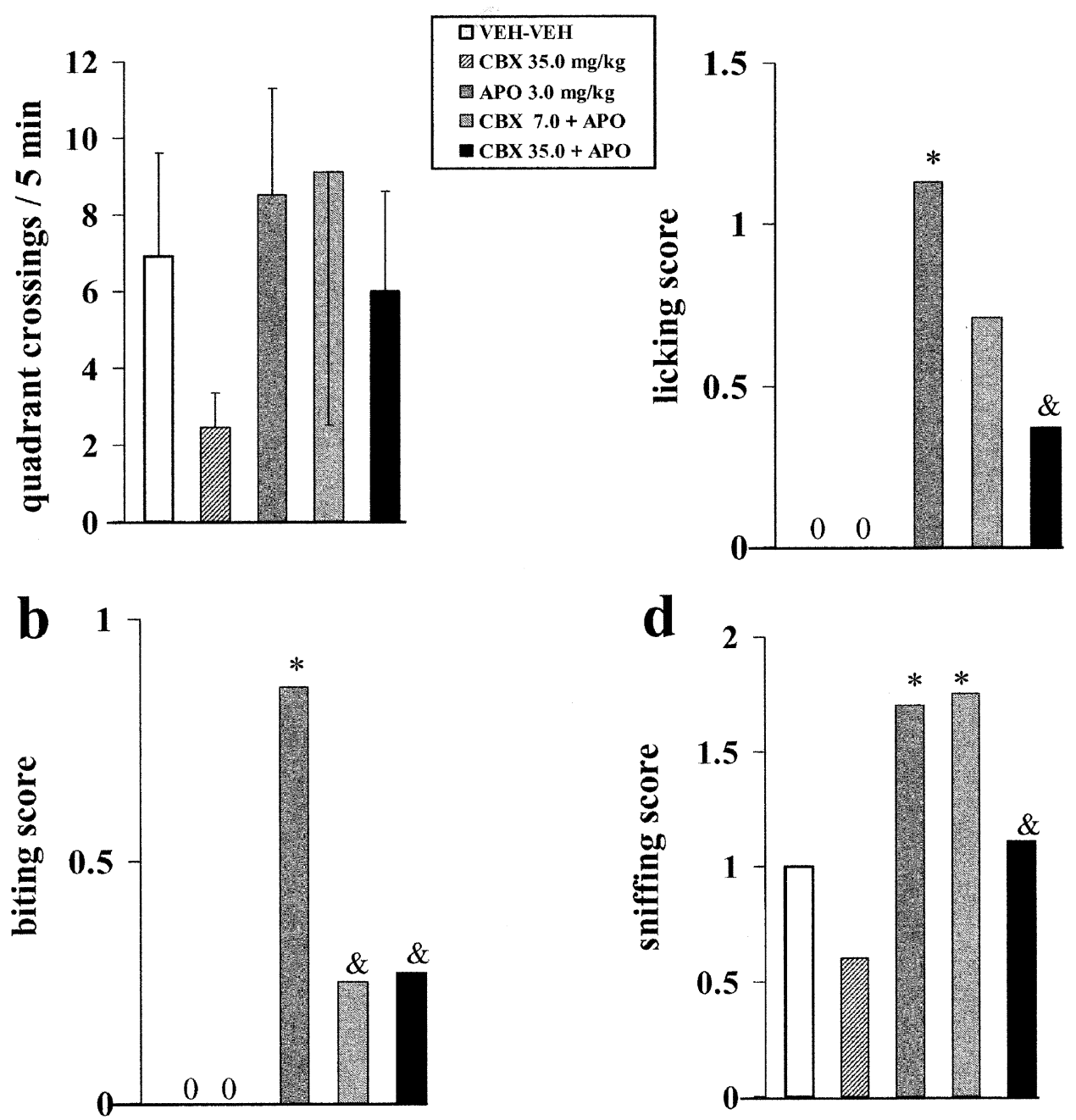

Figure 2. The effect of systemically administered CARB on spontaneous and APOinduced ambulatory activity (a), and biting (b), licking (c), and sniffing (d) stereotypies. APO had no net effect on quadrant crossings, presumably due to the stimulation of locomotion being masked by simultaneous emergence of competing stereotypies. Although there was a trend for CARB to reduce spontaneous locomotion, this was not significant. APO produced a significant increase in licking, biting and sniffing stereotypies. CARB potently antagonized APO-induced biting, having a significant effect at both doses (b), and at the higher dose also significantly blocked APO-induced licking and sniffing (c,d). * $p<.05$ relative to VEH-VEH; \& $p<.05$ relative to $\mathrm{APO}$, and not significantly different from VEHVEH.

dently blocked APO-induced motor activity with the lower dose being not significantly different from either control or APO, and the higher dose being significantly lower than APO and not different than control. Analysis of the concurrent effects on quadrant crossings (a measure of ambulatory activity) and sniffing and oral stereotypies further revealed that while APO had no net effect on quadrant crossings (Figure 2, panel a), it significantly increased biting (Figure 2, panel b), licking (Figure 2, panel c), and sniffing (Figure 2, panel d) stereotypies. This may have resulted from a tendency to increase locomotion concurrent with the emergence of stereotypies that competed with locomotion. Thus, the increase in overall motor activation appeared to be due to APO-induced oral and sniffing stereotypies. CARB had no systematic effect on locomotion following VEH2 or APO (Figure 2, panel a). However, it dose-dependently blocked APO-induced biting (Figure 2, panel b) and licking (Figure 2, panel c) stereotypy (Tukey's comparisons, CARB 7-APO not different from VEH-VEH or
VEH-APO, CARB 35-APO vs. VEH-APO, $p<.05$; vs. VEH-VEH, $p>.4$ ) and also significantly reduced sniffing stereotypy (CARB-APO vs. VEH-APO, $p<.05$; Figure 2, panel d). Thus, it appeared that the reduction in licking, biting, and sniffing resulted in a significant reduction in overall motor activation.

Grooming. In the present experiment, control (VEHVEH) animals initiated and completed grooming sequences during testing (Figure 3), but spent relatively little time grooming overall (data not shown). Thus, grooming was scored as having been initiated (with a paw and head wash) and, in those who initiated, completed with a body (flank) wash. The proportion of all animals tested that displayed grooming initiation alone (paw washing only; Figure 3, solid black area) or initiation and completion of a grooming sequence (Figure 3, hatched area) was recorded for each drug condition. Grooming initiation and completion were affected similarly by drug condition. Grooming initiation and com- 


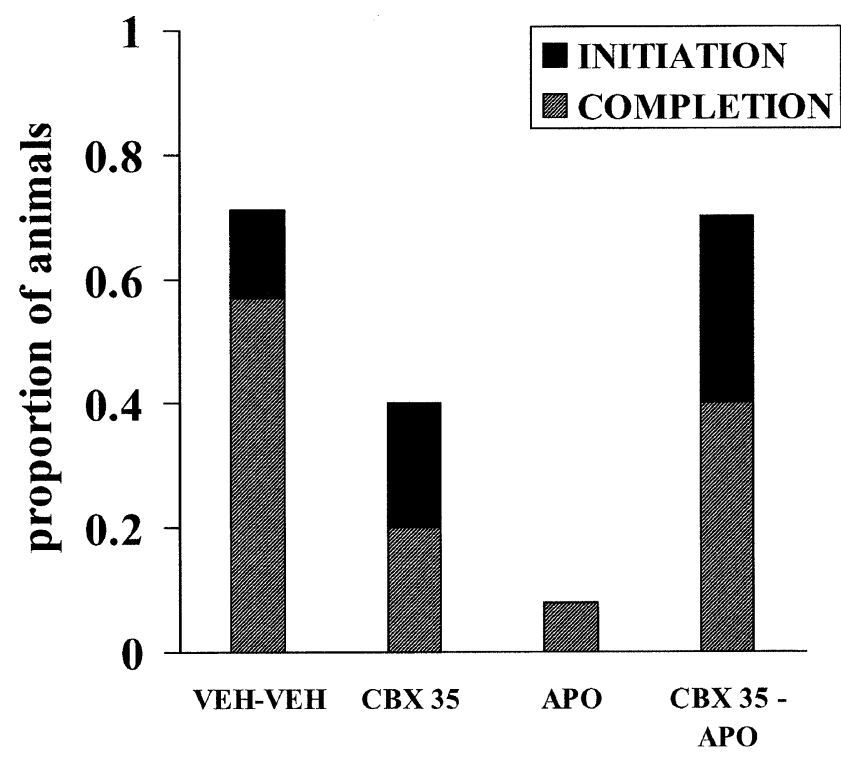

Figure 3. A stacked bar graph showing the effects of CARB on spontaneous and APO-induced changes in initiation and completion of a grooming sequence. Total bar height (height of the black bar) shows the proportion of animals that initiated grooming during the 10-25 min period following the saline or APO injection. The gray bar overlying the black bar shows the proportion of these animals that completed the grooming sequence by progressing from paw wash through snout grooming to flank grooming. Grooming initiation and completion was significantly reduced by CARB $(35.0 \mathrm{mg} /$ $\mathrm{kg})$ or APO $(2.5 \mathrm{mg} / \mathrm{kg})$ administered alone. However, CARB significantly antagonized the negative effects of APO on grooming initiation $(p<.05$ non-parametric binomial test).

pletion were significantly reduced by CARB (CARB$\mathrm{VEH}$ ), and more markedly by APO (VEH-APO; Figure $3 ; p<.05$, binomial comparisons of CARB-VEH and VEH-APO with VEH-VEH). Interestingly, pretreatment with CARB $(35.0 \mathrm{mg} / \mathrm{kg})$ blocked the APO-induced disruption of grooming initiation and completion (i.e. grooming sequencing in the CARB-APO condition was higher than in the VEH-APO condition, and not different from the VEH-VEH condition, binomial test).

\section{Experiment 1b. Effects of Systemic Administration of AEA on the Behavioral Effects of APO}

The following groups were included in the analyses described below: VEH1-VEH2 $(\mathrm{n}=9)$, AEA $(1.5 \mathrm{mg} / \mathrm{kg})$ VEH2 $(\mathrm{n}=5)$, APO-VEH2 $(\mathrm{n}=6)$, AEA $(0.5 \mathrm{mg} / \mathrm{kg})-$ $\operatorname{APO}(n=5)$ and AEA $(1.5 \mathrm{mg} / \mathrm{kg})-\mathrm{APO}(\mathrm{n}=5)$.

Locomotion and Simple Stereotypies. As with Experiment $1 \mathrm{a}$, no effects of time or interaction of time with drug treatment were revealed (Figure 4, panel a). Motor activity during the 10-25 min period after injection of
APO or its vehicle was significantly affected by drug treatment $\left(\mathrm{F}_{4,24}=19.8, p<.001\right.$; Figure 4 , panel b). APO produced a significant increase in activity, relative to VEH-VEH and AEA-VEH (Tukey's comparisons, $p<$ .05) rats. AEA significantly reduced APO-induced motor activity but only at the higher dose; thus AEA 0.5 $\mathrm{mg} / \mathrm{kg}$-APO rats differed significantly from APO but not from controls, while rats pretreated with AEA 0.5 displayed activity levels not different from VEH-APO rats (Figure 4, panel b). Analysis of the concurrent effects on quadrant crossings and sniffing and oral stereotypies further revealed that, as in the CARB testing group, APO had no net effect on quadrant crossings (Figure 5, panel a) but it significantly increased biting (Figure 5, panel b), licking (Figure 5, panel c) and sniffing (Figure 5, panel d) stereotypies. While AEA appeared to be effective in blocking APO-induced sniffing, AEA was similar to CARB in reducing APOinduced licking and biting stereotypy. In addition, at the $1.5 \mathrm{mg} / \mathrm{kg}$ dose, AEA also appeared to "release" the stimulation of locomotion by APO (Figure 5, panel a; Overall $\mathrm{F}=1.75, p=.17$, LSD two-tailed test for AEA 1.5 vs. VEH-VEH, $p<.05)$.

Grooming. Similar to Experiment 1a, APO administration eliminated grooming initiation. However, unlike CARB, AEA was not effective at blocking this effect (data not shown).

\section{Experiment 2. Effect of Intrastriatal CARB on the Behavioral Effects of Systemically- administered APO}

In a total of 25 rats, cannula tip placements were within the ventral striatum ranging from 0.5 to $1.2 \mathrm{~mm}$ anterior to Bregma, 1.5 to $2.5 \mathrm{~mm}$ lateral to the midline and 4.5 to $7.0 \mathrm{~mm}$ ventral to the dural surface (Figure 6). Overall motor activity differed significantly across treatment groups $\left(\mathrm{F}_{3,21}=23.0, p<.001 ; \mathrm{n}=5-8\right.$; Figure 7$)$, with VEH-APO group differing significantly from all other groups, and CARB and CARB-APO not differing from controls. Thus, intrastriatal CARB sufficiently blocked the effects of systemic APO when assessed with a subjective motor activity score. This effect was not due to a net effect on quadrant crossings (Figure 7, panel b) but due mainly to the effects of intra-striatal CARB on oral stereotypies, with biting (Figure 7, panel c) and licking (Figure 7, panel c) being significantly reduced by CARB relative to APO alone $\left(\mathrm{F}_{3,22}>88, p<.001\right.$; Tukey's comparisons). APO-induced sniffing stereotypy was not significantly affected by intra-striatal CARB pretreatment (Figure 7, panel d).

Grooming. Similar to Experiment 1a, APO administration disrupted grooming initiation (data not shown); however, there was no trend for a normalization by intrastriatal CARB. 

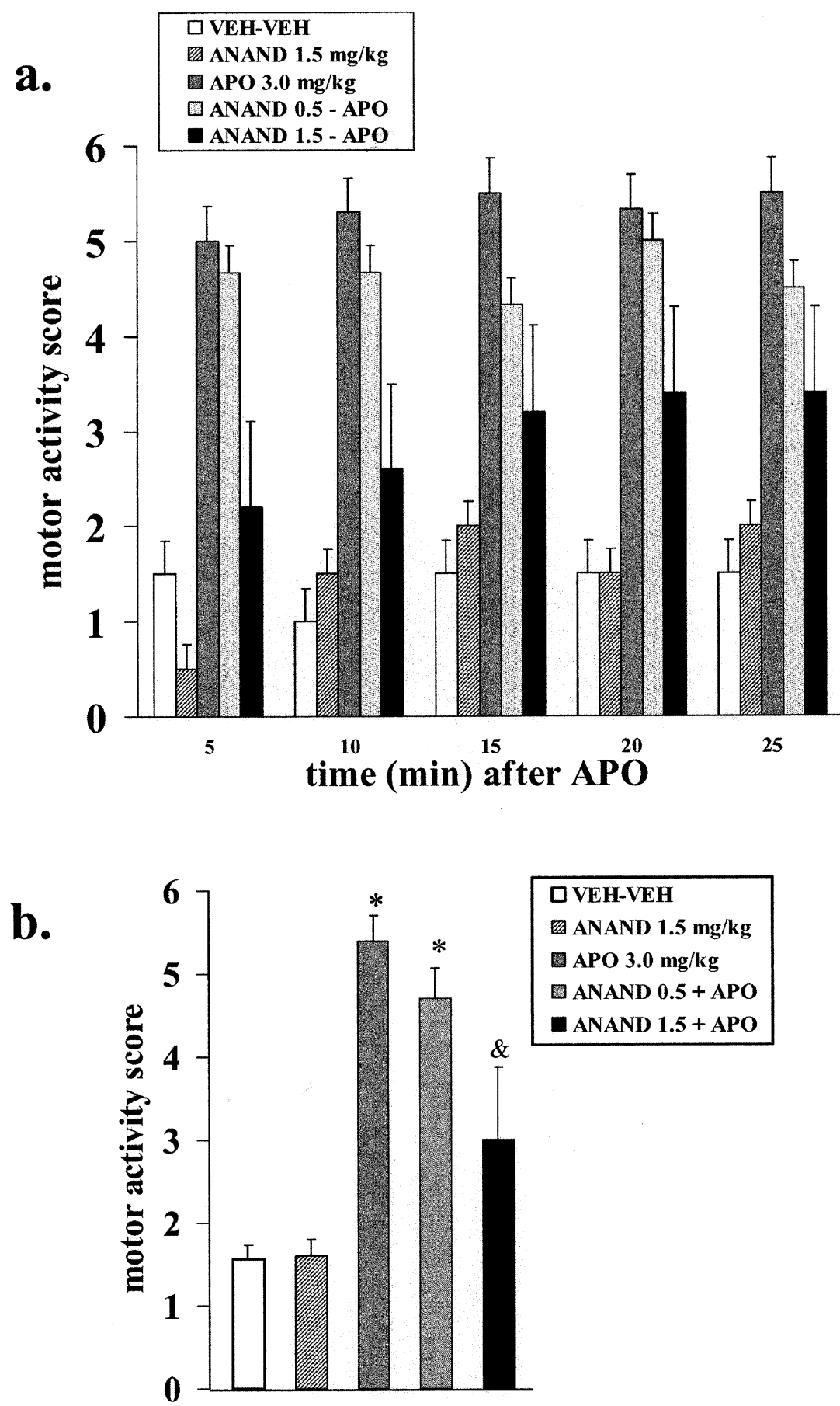

Figure 4. (a) Total motor activity (reflecting both locomotion and stereotypy) during the following injection (i.p. $1.0 \mathrm{ml} / \mathrm{kg}$ ) of saline (open, $\mathrm{n}=9$ ), anandamide (AEA; $1.5 \mathrm{mg} / \mathrm{kg}$; rightward-hatched, $\mathrm{n}=5$ ), apomorphine (APO; 2.5-3.0 mg/kg; dark gray, $\mathrm{n}=6$ ), or AEA $0.5 \mathrm{mg} / \mathrm{kg}$ (light gray, $\mathrm{n}=5$ ) or $1.5 \mathrm{mg} / \mathrm{kg}$ (black, $\mathrm{n}=5$ ) followed by APO. (b) Motor activity averaged during the period of the peak effect of APO (10-25 min post-APO). APO significantly increased motor activity across all time points. While the higher dose of AEA did not have a significant main effect on spontaneous total motor activity, it significantly reduced APO-induced motor activity. ${ }^{*} p<.05$ relative to $\mathrm{VEH}-\mathrm{VEH}$; $\& p<.05$ relative to $\mathrm{APO}$, and not significantly different from VEH-VEH.

\section{DISCUSSION}

In the present study, APO-induced simple oral and sniffing stereotypies were selectively blocked by systemic administration of two different gap junction inactivators. Moreover, local gap junction inactivation within the ventral striatum selectively blocked APOinduced oral stereotypies. We propose that the present data taken with previous studies on the pharmacology of APO-induced effects on behavior and electrotonic coupling in the striatum indicates that a major mecha- nism by which these gap junction inactivators blocked APO-induced stereotypy is by blocking a D2 receptormediated increase in electrotonic coupling.

\section{The Specificity of the Effects of CARB and AEA on Electrotonic Coupling}

As reviewed in the introduction, although both CARB and AEA have a number of physiological actions, the major action that these drugs have in common is the inactivation of gap junctions. The effects of systemic CARB 
a
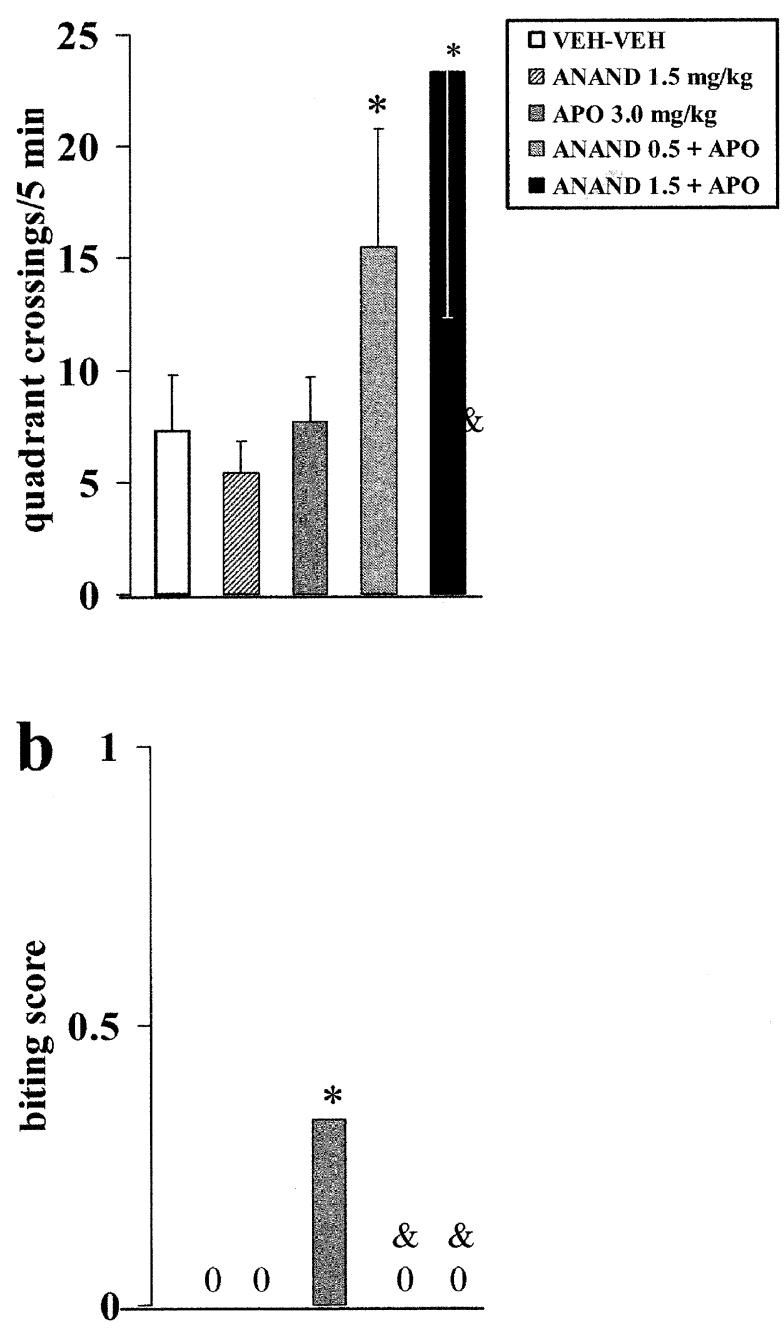

c
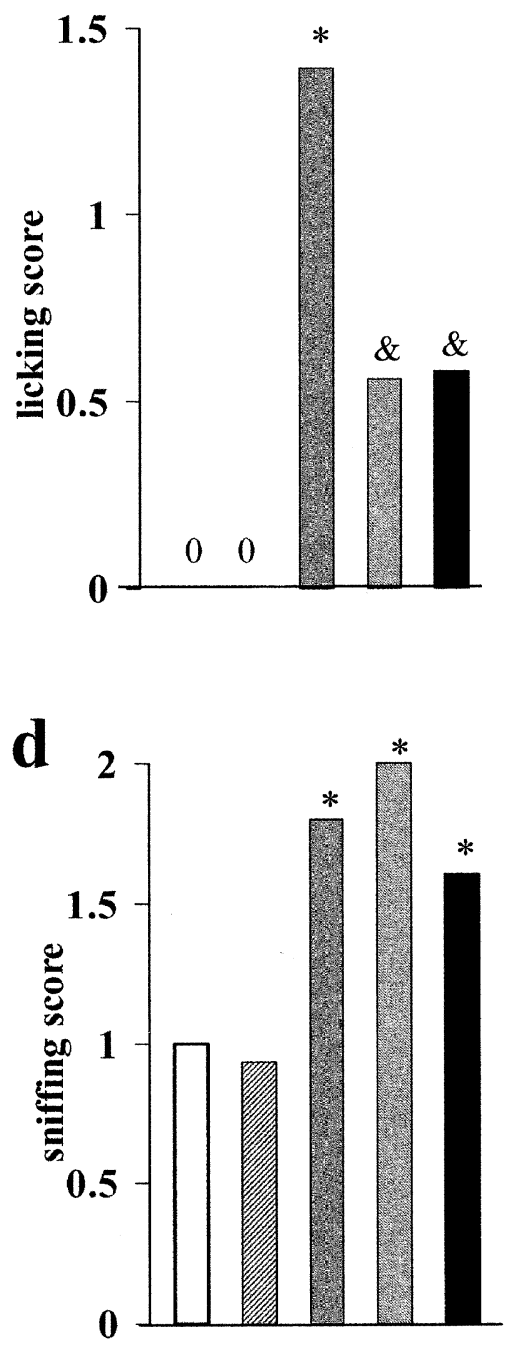

Figure 5. The effect of systemically-administered AEA on spontaneous and APO-induced ambulatory activity (a), and biting (b), licking (c), and sniffing (d) stereotypies. a. As in the CARB experiment, APO had no net effect on quadrant crossings. AEA increased quadrant crossings following $\mathrm{APO}$ injection, presumably by eliminating competing stereotypies. b. APO induced a significantly level of stereotypic biting which was potently blocked by both doses of AEA. c. APO-induced licking was also significantly blocked by both doses of AEA. d. APO-induced sniffing was not effectively blocked by systemic injection of AEA up to $1.5 \mathrm{mg} /$ kg. ${ }^{*} p<.05$ relative to VEH-VEH; \& $p<.05$ relative to APO, and not significantly different from VEH-VEH. administration that could interfere with the measurement of behavior include changes in kidney function and hypertension (Gomez-Sanchez and Gomez-Sanchez 1992). However these effects are achieved with chronic administration or with doses higher than those used in this study. Similarly, at doses several times higher than those used in this study, AEA produces ataxia, hypomotility (Aceto et al. 1998; Crawley et al. 1993), and acute hypotension (Garcia et al. 2001). Thus, given the relatively low doses used in the present study it is unlikely that the reductions in APO-mediated behaviors were secondary to these effects of CARB or AEA per se.

Because not only AEA, but also its inactivating enzyme fatty acid amide hydrolase, and multiple effector sites, including voltage gated calcium channels and CB1 receptors, are all located on basal ganglia neurons, it is important to consider mechanisms other than gap junction conductance that could have contributed to the ability of AEA to block APO-induced stereotypies. In addition to the inactivation of gap junction conductance, possible mechanisms of action of AEA include inhibition of voltage-gated calcium channels (Chemin et al. 2001), enhancement of specific potassium channels (White et al. 2001) and activation of CB1 receptors (Ameri 1999). In the present study, the effects of AEA on calcium and potassium channels would appear to be limited, since the major physiologic change produced by these actions, vasorelaxation and a decrease in systemic vascular resistance (Garcia et al. 2001), require doses significantly higher than those used to block APO-induced stereotypy. Similarly, large changes in calcium and potassium conductance in basal ganglia neurons or local cerebral blood vessels might be expected to cause marked effects on cerebral blood flow or basal ganglia function: effects that are not observed at the highest dose used in this study (Stein et al. 1998; present data). Thus, although there is evidence for interactions among AEA, calcium, and potassium chan- 


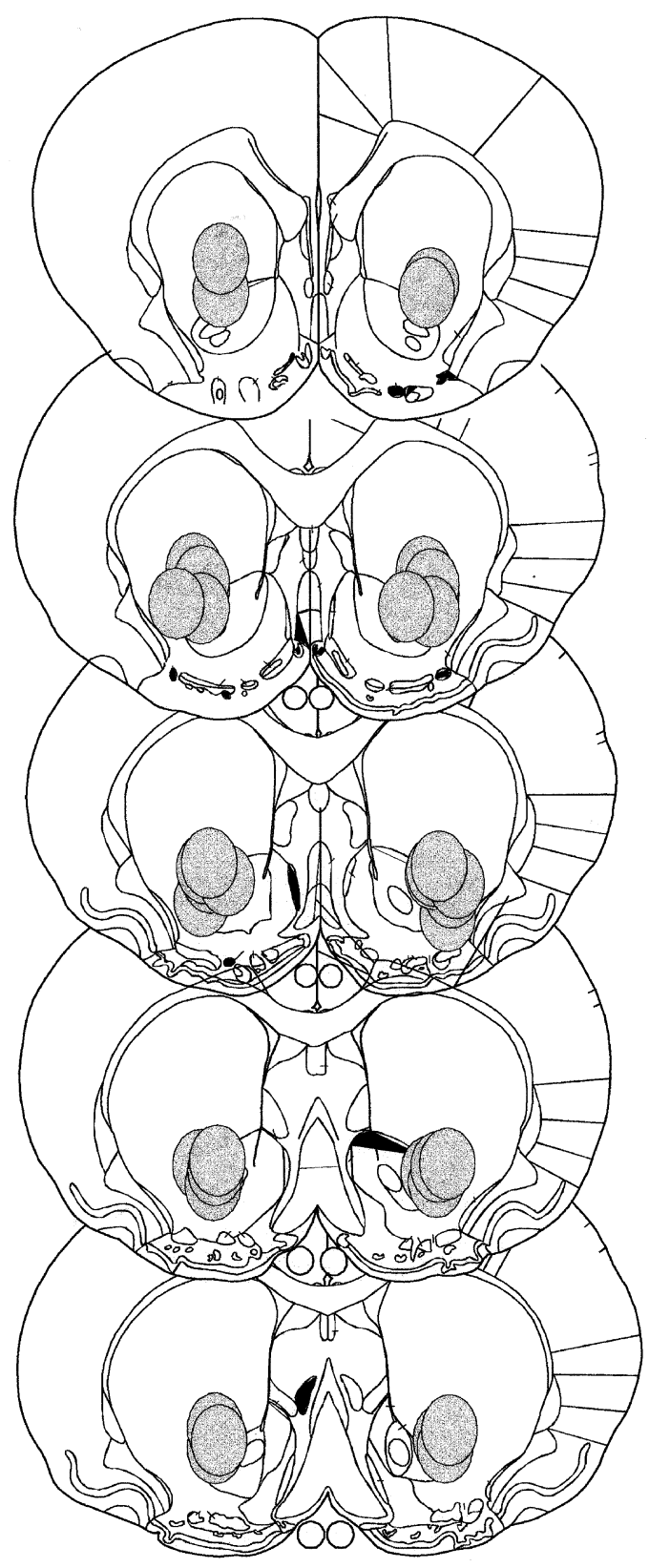

Figure 6. A schematic diagram showing the injection sites for each subject in the intra-striatal CARB experiment (Experiment 2; see text). The ovals show the area around the tip of each cannula that appeared to be disrupted.

nels, and junctions in mediating intercellular communication (Schweighofer et al. 1999), large changes in voltage-gated ion channels are unlikely to have mediated the behavioral effects observed in the present study.

There is considerable but not complete overlap in the brain regions enriched in AEA and its inactivating enzyme, fatty acid amide hydrolase (Di Marzo et al. 2000) and CB1 binding sites (Sanudo-Pena et al. 1999). How- ever, the doses of AEA used in the present study are below those commonly used to produce CB1 receptormediated effects. Furthermore the behaviors produced by CB1 receptor stimulation (e.g. hypomotility) are quite different from those observed at the doses used in the present study (e.g. increases in locomotion). This is consistent with data showing that the effects of AEA on locomotor activity are biphasic, with increases in spontaneous locomotion or antagonism of cannabinoidinduced hypermotility occurring at doses $<0.01 \mathrm{mg} /$ $\mathrm{kg}$ and hypomotility occurring at doses between 10-100 $\mathrm{mg} / \mathrm{kg}$. Importantly, a significant proportion of the motor effects of AEA, as with its effects on gap junction coupling, occurs independent of CB receptors (Ameri 1999; Di Marzo et al. 2000). Taking the above evidence together with the convergence of the effects of CARB and AEA on gap junction coupling and behavior, we conclude that electrotonic coupling may be a major substrate for interaction between AEA and DA systems in the basal ganglia. However, it is likely that this mechanism interacts with other actions of AEA (e.g. on CB1 receptors) in the basal ganglia to affect psychomotor behavior.

\section{The Pharmacology of the APO-induced Stereotypies Blocked by AEA and CARB}

The DA pharmacology of APO-induced stereotypies has been well-characterized. Specific stereotypies are mediated by specific regions within the striatum by an interaction between D1-type and D2-type DA receptors (Cameron and Crocker 1989; Kelly et al. 1975; Romero et al. 1995; Schmidt 1986). Whereas locomotion and head and sniffing stereotypies are mediated by a number of sub-circuits in dorsal and ventral striatum (Delfs and Kelley 1990; Koene et al. 1993; Cameron and Crocker 1989; Schmidt 1986), oral stereotypies such as biting and licking are regulated primarily by the medial or lateral ventral striatum (Delfs and Kelley 1990; Downes and Waddington 1993; Koene et al. 1993). Sniffing, biting and licking are characteristic effects of D2 receptor over-stimulation (i.e. produced by D2 agonists) (Davidkova et al. 1998; Fowler and Liou 1994; Wang et al. 2000), but also require a minimal level of D1 receptor stimulation (Beninger et al. 1991; Mashurano and Waddington 1986). Unlike most simple stereotypies and locomotion, grooming appears mainly to be a behavioral sequence mediated by D1 receptor stimulation in the central and dorsal striatum (Cromwell et al. 1998; Downes and Waddington 1993; Molloy and Waddington 1984b). The effects on grooming observed in the present study were intriguing, given the plausible role of gap junction in behavioral sequencing. The effectiveness of systemic AEA and CARB in blocking oral and sniffing stereotypies and the selective blockade of oral stereotypies by ventral striatal administration of 

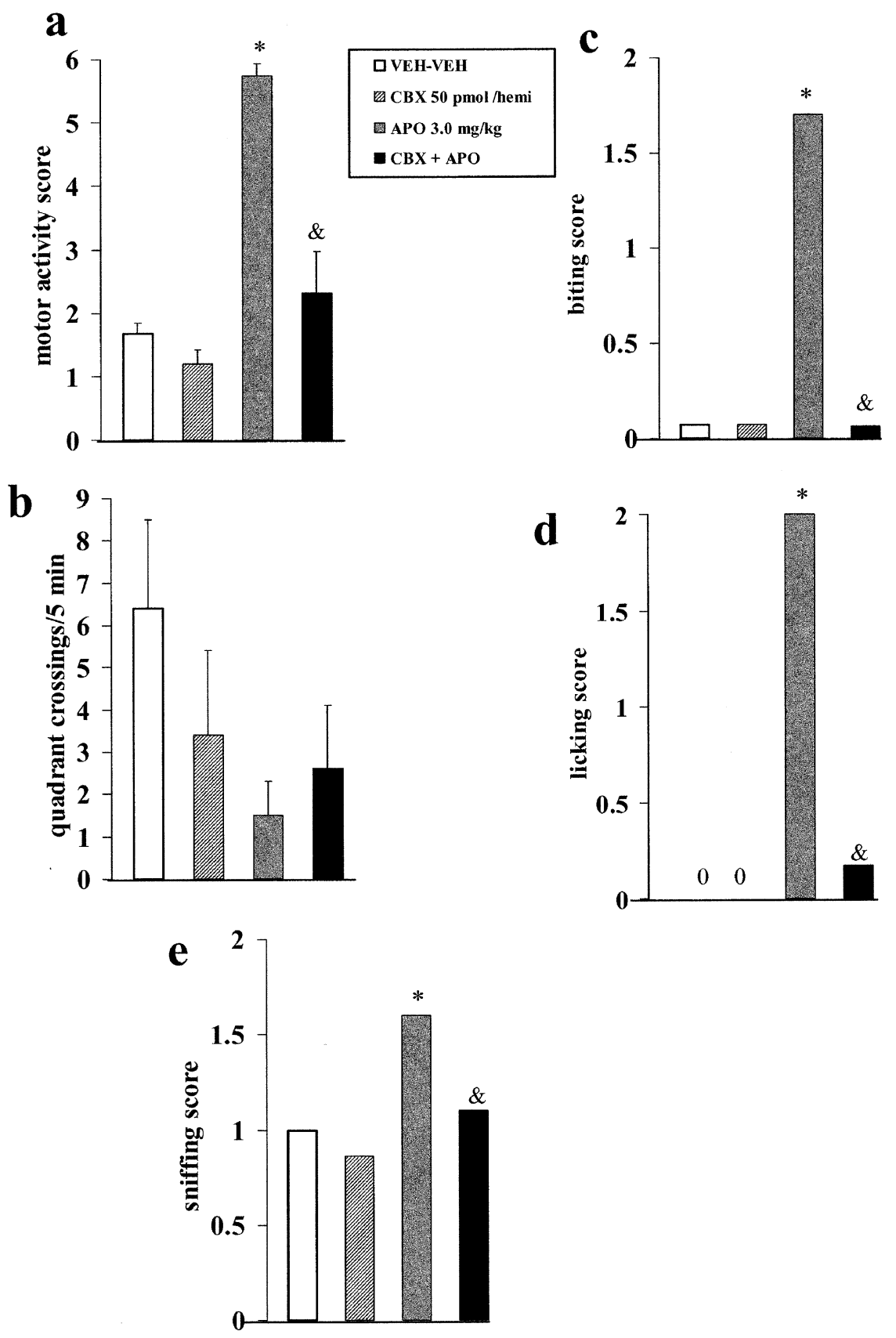

CARB is consistent with the idea that D2 receptor-mediated increases in gap junction conductance (Onn and Grace 1994) are necessary in the expression of these stereotypies.

\section{The Role of Gap Junctions and Dopamine in Signal Flow across Cortical-basal Ganglia Circuits and the Regulation of Stereotypic Behavior}

The effects of CARB and AEA on APO-induced stereotypies and spontaneous grooming indicate that intercellular electrotonic coupling is involved in basal ganglia regulation of movement, and may be necessary for the
Figure 7. The effects of local administration of CARB into the ventral striatum on the motor stereotypies induced by systemic APO. Data are shown from groups receiving intracranial vehicle followed by systemic vehicle (VEH1VEH2; open bars, $\mathrm{n}=8$ ), intra-striatal CARB (50 pmol/hemi)-systemic VEH2 (hatched bars, $\mathrm{n}=5$ ), intra-striatal vehicle-systemic APO (gray bars, $\mathrm{n}=$ 5) and intra-striatal CARB-systemic APO (black bars, $n=7$ ). Similar to the effects of systemic CARB, intra-striatal CARB blocked the effects of systemic APO on total motor activity (a). This appeared to be due not to an effect on net ambulatory activity (b) but to potent blockade of APO-induced stereotypic biting (c) and licking (d). Intra-striatal CARB did not have a significant effect on APO-induced stereotypic sniffing (d). ${ }^{*} p<.05$ relative to VEH-VEH; \& $p<.05$ relative to APO, and not significantly different from VEH-VEH. expression of these basal ganglia-mediated behaviors in particular. Studies in multiple brain regions showing that electrical coupling between neurons and/or glia appears to be necessary for synchronized neural activity within these regions and the highly stereotyped behaviors mediated by such activity (Alvarez-Maubecin et al. 2000; Bou-Flores and Berger 2001; Perez Velazquez and Carlen 2000; Rothwell 1998; van den Pol and Dudek 1993). Extrapolating from these results, we propose that electrotonic coupling among basal ganglia cells may be one part of a process in which information flows across "microcircuits" in the basal ganglia, allowing behavioral switching and the completion of behavioral sequences. 
Our previous data show that striatal coupling can be potently altered by corticostriatal drive acting via nitric oxide (O'Donnell and Grace 1997). We propose that, under the modulatory control of the DA system, the cortex functions to guide a sequence of motor patterns from one simple motor set to another via sequential activation and de-activation of excitation and electrical coupling among sets of functionally related neurons. The specific role of DA through D2 receptors may be to regulate the size and time course of an electrotonicallycoupled network (Cepeda et al. 1989; Onn and Grace 1994). On the other hand, abnormally high $D 2$ receptor activation would lead to persistent coupling in the most readily-activated striatal circuits (Onn and Grace 1994). This pathological neuronal process could prevent a microcircuit from "exiting out" of its sequential activation and prevent behavioral switching (Jaspers et al. 1990; Ridley 1994). Such a failure to "release" a component of a motor response would thus lead to re-entrant, repetitive activation of a simple motor component such as would occur during stereotypy when it occurs within corticostriatal motor circuits. In contrast, the selective activation of coupling within limbic circuits that occurs upon withdrawal from repeated amphetamine administration (Onn and Grace 2000) may also lead to a type of "cognitive" stereotypy, such as the perseverative drug-seeking behavior demonstrated as a consequence of drug abuse. Within this context, the present findings on the actions of gap junction inactivators may have relevance for diseases such as obsessive-compulsive disorder, drug abuse, and schizophrenia, or other disorders that are associated with disruption of cognitive and/or motor sequencing (Berger et al. 1989; Cools et al. 2001; Hymas et al. 1991; Ridley 1994; Sullivan et al. 2001).

\section{ACKNOWLEDGMENTS}

This work was supported by USPHS awards MH 45156, MH 57440 and MH 29670 (A.A.G.), and Young Investigator (H.M.) and Distinguished Investigator (A.A.G.) awards from the National Alliance for Research on Schizophrenia and Depression.

\section{REFERENCES}

Abrams DR, Bruno JP (1992): Ontogeny of apomorphineinduced stereotypy and its D1 and D2 receptor mediation in rats depleted of dopamine as neonates. Dev Psychobiol 25:475-495

Aceto MD, Scates SM, Razdan RK, Martin BR (1998): Anandamide, an endogenous cannabinoid, has a very low physical dependence potential. J Pharmacol Exp Ther 287:598-605

Aldridge JW, Berridge KC (1998): Coding of serial order by neostriatal neurons: a "natural action" approach to movement sequence. J Neurosci 18:2777-2787
Aldridge JW, Berridge KC, Herman M, Zimmer L (1993): Neuronal coding of serial order: syntax of grooming in the neostriatum. Psyhcological Sciences 4:391-395

Alvarez-Maubecin V, Garcia-Hernandez F, Williams JT, Van Bockstaele EJ (2000): Functional coupling between neurons and glia. J Neurosci 20:4091-4098

Ameri A (1999): The effects of cannabinoids on the brain. Prog Neurobiol 58:315-348

Armanini D, Karbowiak I, Krozowski Z, Funder JW, Adam WR (1982): The mechanism of mineralocorticoid action of carbenoxolone. Endocrinology 111:1683-1686

Bannerman P, Nichols W, Puhalla S, Oliver T, Berman M, Pleasure D (2000): Early migratory rat neural crest cells express functional gap junctions: evidence that neural crest cell survival requires gap junction function. J Neurosci Res 61:605-615

Belluardo N, Mudo G, Trovato-Salinaro A, Le Gurun S, Charollais A, Serre-Beinier V, Amato G, Haefliger JA, Meda P, Condorelli DF (2000): Expression of connexin36 in the adult and developing rat brain. Brain Res 865: 121-138

Beninger RJ, Mazurski EJ, Hoffman DC (1991): Receptor subtype-specific dopaminergic agents and unconditioned behavior. Pol J Pharmacol Pharm 43:507-528

Bennett SA, Arnold JM, Chen J, Stenger J, Paul DL, Roberts DC (1999): Long-term changes in connexin32 gap junction protein and mRNA expression following cocaine self-administration in rats. Eur J Neurosci 11:3329-3338

Berger HJ, van Hoof JJ, van Spaendonck KP, Horstink MW, van den Bercken JH, Jaspers R, Cools AR (1989): Haloperidol and cognitive shifting. Neuropsychologia 27: 629-639

Berridge KC, Aldridge JW (2000a): Super-stereotypy I: enhancement of a complex movement sequence by systemic dopamine D1 agonists. Synapse 37:194-204

Berridge KC, Aldridge JW (2000b): Super-stereotypy II: enhancement of a complex movement sequence by intraventricular dopamine D1 agonists. Synapse 37:205215

Boger DL, Sato H, Lerner AE, Guan X, Gilula NB (1999): Arachidonic acid amide inhibitors of gap junction cellcell communication. Bioorg Med Chem Lett 9:1151-1154

Bou-Flores C, Berger AJ (2001): Gap junctions and inhibitory synapses modulate inspiratory motoneuron synchronization. J Neurophysiol 85:1543-1551

Braun AR, Chase TN (1986): Obligatory D1/D2 receptor interaction in the generation of dopamine agonist related behaviours. Eur J Pharmacol 131:301-306

Byrnes EM, Abrams D, Bruno JP (1994): Co-activation of D1and D2-like receptors is unnecessary for stimulated motor behavior in rats depleted of dopamine during development. Behav Brain Res 61:205-214

Cameron DL, Crocker AD (1989): Localization of striatal dopamine receptor function by central injection of an irreversible receptor antagonist. Neuroscience 32:769778

Cepeda C, Walsh JP, Hull CD, Howard SG, Buchwald NA, Levine MS (1989): Dye-coupling in the neostriatum of the rat: I. Modulation by dopamine-depleting lesions. Synapse 4:229-237 
Chemin J, Monteil A, Perez-Reyes E, Nargeot J, Lory P (2001): Direct inhibition of T-type calcium channels by the endogenous cannabinoid anandamide. EMBO J 20:7033-7040

Cools R, Barker RA, Sahakian BJ, Robbins TW (2001): Mechanisms of cognitive set flexibility in Parkinson's disease. Brain 124:2503-2512

Costa B, Vailati S, Colleoni M (1999): SR 141716A, a cannabinoid receptor antagonist, reverses the behavioural effects of anandamide-treated rats. Behav Pharmacol 10:327-331

Crawley JN, Corwin RL, Robinson JK, Felder CC, Devane WA, Axelrod J (1993): Anandamide, an endogenous ligand of the cannabinoid receptor, induces hypomotility and hypothermia in vivo in rodents. Pharmacol Biochem Behav 46:967-972

Cromwell HC, Berridge KC (1996): Implementation of action sequences by a neostriatal site: a lesion mapping study of grooming syntax. J Neurosci 16:3444-3458

Cromwell HC, Berridge KC, Drago J, Levine MS (1998): Action sequencing is impaired in D1A-deficient mutant mice. Eur J Neurosci 10:2426-2432

Davidkova G, Zhou LW, Morabito M, Zhang SP, Weiss B (1998): D2 dopamine antisense RNA expression vector, unlike haloperidol, produces long-term inhibition of D2 dopamine-mediated behaviors without causing up-regulation of D2 dopamine receptors. J Pharmacol Exp Ther 285:1187-1196

Davidson JS, Baumgarten IM (1988): Glycyrrhetinic acid derivatives: a novel class of inhibitors of gap-junctional intercellular communication. Structure-activity relationships. J Pharmacol Exp Ther 346:1104-1107

De Petrocellis L, Harrison S, Bisogno T, Tognetto M, Brandi I, Smith GD, Creminon C, Davis JB, Geppetti P, Di Marzo V (2001): The vanilloid receptor (VR1)-mediated effects of anandamide are potently enhanced by the cAMP-dependent protein kinase. J Neurochem 77:16601663

De Petrocellis L, Melck D, Palmisano A, Bisogno T, Laezza C, Bifulco M, Di Marzo V (1998): The endogenous cannabinoid anandamide inhibits human breast cancer cell proliferation. Proc Natl Acad Sci USA 95:8375-8380

Delfs JM, Kelley AE (1990): The role of D1 and D2 dopamine receptors in oral stereotypy induced by dopaminergic stimulation of the ventrolateral striatum. Neuroscience 39:59-67

Di Marzo V, Breivogel CS, Tao Q, Bridgen DT, Razdan RK, Zimmer AM, Zimmer A, Martin BR (2000): Levels, metabolism, and pharmacological activity of anandamide in $\mathrm{CB}(1)$ cannabinoid receptor knockout mice: evidence for non- $\mathrm{CB}(1)$, non- $\mathrm{CB}(2)$ receptor-mediated actions of anandamide in mouse brain. J Neurochem 75:2434-2444

Downes RP, Waddington JL (1993): Grooming and vacuous chewing induced by SK\&F 83959, an agonist of dopamine 'D1-like' receptors that inhibits dopamine-sensitive adenylyl cyclase. Eur J Pharmacol 234:135-136

Fowler SC, Liou JR (1994): Microcatalepsy and disruption of forelimb usage during operant behavior: differences between dopamine D1 (SCH-23390) and D2 (raclopride) antagonists. Psychopharmacology (Berl) 115:24-30
Fride E, Mechoulam R (1993): Pharmacological activity of the cannabinoid receptor agonist, anandamide, a brain constituent. Eur J Pharmacol 231:313-314

Garcia N Jr, Jarai Z, Mirshahi F, Kunos G, Sanyal AJ (2001): Systemic and portal hemodynamic effects of anandamide. Am J Physiol Gastrointest Liver Physiol 280:G14-20

Gomez-Sanchez EP, Gomez-Sanchez CE (1992): Central hypertensinogenic effects of glycyrrhizic acid and carbenoxolone. Am J Physiol 263:E1125-E1130

Horikawa HP, Nakazato T, Hikosaka O (1997): Duration of catalepsy correlates with increased intrastriatal sulpiride. Eur J Pharmacol 326:15-21

Hymas N, Lees A, Bolton D, Epps K, Head D (1991): The neurology of obsessional slowness. Brain 114:2203-2233

Jaspers RM, de Vries TJ, Cools AR (1990): Effects of intrastriatal apomorphine on changes in switching behaviour induced by the glutamate agonist AMPA injected into the cat caudate nucleus. Behav Brain Res 37:247-254

Jefferys JG (1995): Nonsynaptic modulation of neuronal activity in the brain: electric currents and extracellular ions. Physiol Rev 75:689-723

Kelly PH, Seviour PW, Iversen SD (1975): Amphetamine and apomorphine responses in the rat following 6-OHDA lesions of the nucleus accumbens septi and corpus striatum. Brain Res 94:507-522

Koene P, Prinssen EP, Cools AR (1993): Involvement of the nucleus accumbens in oral behaviour in the freely moving rat. Eur J Pharmacol 233:151-156

Mashurano M, Waddington JL (1986): Stereotyped behaviour in response to the selective D-2 dopamine receptor agonist RU 24213 is enhanced by pretreatment with the selective D-1 agonist SK\&F 38393. Neuropharmacology 25:947-949

Matsumoto N, Hanakawa T, Maki S, Graybiel AM, Kimura M (1999): Role of [corrected] nigrostriatal dopamine system in learning to perform sequential motor tasks in a predictive manner. J Neurophysiol 82:978-998

Molloy AG, Waddington JL (1984a): Dopaminergic behavior stereospecific promoted by the D1 agonist SKF 38393 and selectively blocked by the D1 antagonist $\mathrm{SCH}$ 23390. Psychopharmacology (Berl) 82:409-410

Molloy AG, Waddington JL (1984b): Dopaminergic behaviour stereospecific promoted by the D1 agonist R-SK \& F 38393 and selectively blocked by the D1 antagonist SCH 23390. Psychopharmacology (Berl) 82:409-410

O'Donnell P, Grace AA (1997): Cortical afferents modulate striatal gap junction permeability via nitric oxide. Neuroscience $76: 1-5$

Onn SP, Grace AA (1994): Dye coupling between rat striatal neurons recorded in vivo: compartmental organization and modulation by dopamine. J Neurophysiol 71:19171934

Onn SP, Grace AA (1995): Repeated treatment with haloperidol and clozapine exerts differential effects on dye coupling between neurons in subregions of striatum and nucleus accumbens. J Neurosci 15:7024-7036

Onn SP, Grace AA (1999): Alterations in electrophysiological activity and dye coupling of striatal spiny and aspiny neurons in dopamine-denervated rat striatum recorded in vivo. Synapse 33:1-15 
Onn SP, Grace AA (2000): Amphetamine withdrawal alters bistable states and cellular coupling in rat prefrontal cortex and nucleus accumbens neurons recorded in vivo. J Neurosci 20:2332-2345

Paxinos G, Watson C (1996): The rat brain in stereotaxic coordinates, 2nd ed. San Diego, CA, Academic Press

Pedro BM, Pilowsky LS, Costa DC, Hemsley DR, Ell PJ, Verhoeff NP, Kerwin RW, Gray NS (1994): Stereotypy, schizophrenia and dopamine D2 receptor binding in the basal ganglia. Psychol Med 24:423-429

Peinado A, Yuste R, Katz LC (1993): Gap junctional communication and the development of local circuits in neocortex. Cereb Cortex 3:488-498

Perez Velazquez JL, Carlen PL (2000): Gap junctions, synchrony and seizures. Trends Neurosci 23:68-74

Ridley RM (1994): The psychology of perserverative and stereotyped behaviour. Prog Neurobiol 44:221-231

Roberts NB, Taylor WH (1980): The actions of carbenoxolone on enzymes and their relation to its therapeutic effect. Scand J Gastroenterol Suppl 65:11-17

Roerig B, Feller MB (2000): Neurotransmitters and gap junctions in developing neural circuits. Brain Res Brain Res Rev 32:86-114

Romero J, Garcia L, Cebeira M, Zadrozny D, FernandezRuiz JJ, Ramos JA (1995): The endogenous cannabinoid receptor ligand, anandamide, inhibits the motor behavior: role of nigrostriatal dopaminergic neurons. Life Sci 56:2033-2040

Rothwell JC (1998): Physiology and anatomy of possible oscillators in the central nervous system. Mov Disord 13:24-28

Rozental R, Srinivas M, Spray DC (2001): How to close a gap junction channel: efficacies and potencies of uncoupling agents. In Giaume C (ed), Connexin Methods and Protocols (Methods in Molecular Biology). Totowa, NJ, Humana Press, pp 447-476

Sanudo-Pena MC, Tsou K, Walker JM (1999): Motor actions of cannabinoids in the basal ganglia output nuclei. Life Sci 65:703-713

Schmidt WJ (1986): Intrastriatal injection of DL-2-amino-5- phosphonovaleric acid (AP-5) induces sniffing stereotypy that is antagonized by haloperidol and clozapine. Psychopharmacology (Berl) 90:123-130

Schweighofer N, Doya K, Kawato M (1999): Electrophysiological properties of inferior olive neurons: A compartmental model. J Neurophysiol 82:804-817

Sibley DR (1999): New insights into dopaminergic receptor function using antisense and genetically altered animals. Ann Rev Pharmacol Toxicol 39:313-341

Stein EA, Fuller SA, Edgemond WS, Campbell WB (1998): Selective effects of the endogenous cannabinoid arachidonylethanolamide (anandamide) on regional cerebral blood flow in the rat. Neuropsychopharmacology 19: 481-491

Stewart PM, Wallace AM, Atherden SM, Shearing $\mathrm{CH}$, Edwards CR (1990): Mineralocorticoid activity of carbenoxolone: contrasting effects of carbenoxolone and liquorice on 11 beta-hydroxysteroid dehydrogenase activity in man. Clinical Science 78:49-54

Sullivan EV, Fama R, Shear PK, Cahn-Weiner DA, Stein M, Zipursky RB, Pfefferbaum A (2001): Motor sequencing deficits in schizophrenia: a comparison with Parkinson's disease. Neuropsychology 15:342-350

Szechtman H, Culver K, Eilam D (1999): Role of dopamine systems in obsessive-compulsive disorder (OCD): implications from a novel psychostimulant-induced animal model. Pol J Pharmacol 51:55-61

van den Pol AN, Dudek FE (1993): Cellular communication in the circadian clock, the suprachiasmatic nucleus. Neuroscience 56:793-811

Venance L, Piomelli D, Glowinski J, Giaume C (1995): Inhibition by anandamide of gap junctions and intercellular calcium signalling in striatal astrocytes. Nature 376:590-594

Wang Y, Xu R, Sasaoka T, Tonegawa S, Kung MP, Sankoorikal EB (2000): Dopamine D2 long receptor-deficient mice display alterations in striatum-dependent functions. J Neurosci 20:8305-8314

White R, Ho WS, Bottrill FE, Ford WR, Hiley CR (2001): Mechanisms of anandamide-induced vasorelaxation in rat isolated coronary arteries. Br J Pharmacol 134:921-929 